\title{
Nasal Obstruction as a Potential Factor Contributing to Hypoxemia in Obstructive Sleep Apnea
}

This article was published in the following Dove Press journal:

Nature and Science of Sleep

\author{
Ming-Chin Lan ${ }^{1,2}$ \\ Ming-Ying Lan (D) ${ }^{3,4}$ \\ Edward C Kuan ${ }^{5}$ \\ Yun-Chen Huang ${ }^{1,2}$ \\ Tung-Tsun Huang ${ }^{1,2}$ \\ Yen-Bin Hsu (iD) 3,4 \\ 'Department of Otolaryngology-Head \\ and Neck Surgery, Taipei Tzu Chi \\ Hospital, Buddhist Tzu Chi Medical \\ Foundation, New Taipei City, Taiwan; \\ ${ }^{2}$ School of Medicine, Tzu Chi University, \\ Hualien, Taiwan; ${ }^{3}$ Department of \\ Otolaryngology-Head and Neck Surgery, \\ Taipei Veterans General Hospital, Taipei, \\ Taiwan; ${ }^{4}$ School of Medicine, National \\ Yang-Ming University, Taipei, Taiwan; \\ ${ }^{5}$ Department of Otolaryngology-Head \\ and Neck Surgery, University of \\ California, Irvine, Orange, CA, USA
}

Correspondence: Yen-Bin Hsu Department of Otolaryngology-Head and Neck Surgery, Taipei Veterans General Hospital, No. 20I, Sec. 2, Shipai Road, Beitou District, Taipei City 11217, Taiwan Tel +886-2-28741210

Fax +886-2-28757338

Email yenbinhsu@gmail.com
Purpose: This study aimed to evaluate the correlation between nasal resistance and oxygen desaturation to better elucidate the role of nasal obstruction in the pathophysiology of obstructive sleep apnea (OSA).

Patients and Methods: Eighty-eight OSA patients aged between 22 and 77 years were enrolled in this study. Nasal resistance was measured at pressures of 75, 150, and $300 \mathrm{~Pa}$, with the patients first in the seated position than in the supine position. Relationships between the oximetric variables and nasal resistance in the seated and supine positions were analyzed.

Results: From seated to supine position, a statistically significant increase in nasal resistance was observed at pressures of 75 and $150 \mathrm{~Pa}(\mathrm{p}=0.001$ and $\mathrm{p}=0.006$, respectively). Significant positive correlations were noted between nasal resistance in the supine position at $75 \mathrm{~Pa}$ (SupineNR75) and oximetry variables, including oxygen desaturation index (ODI, $\mathrm{p}=0.015$ ) and the percentage of total time with oxygen saturation level lower than $90 \%$ ( $\mathrm{T}<90 \%$, $\mathrm{p}=0.012$ ). However, significant positive correlations existed only in moderate to severe OSA when the study group was further divided into two subgroups (mild vs moderate to severe OSA). Body mass index $(\beta=0.476, p<0.001)$ and SupineNR75 $(\beta=0.303, p=0.004)$ were identified as independent predictors for increased ODI.

Conclusion: Nasal resistance in the supine position measured at $75 \mathrm{~Pa}$ significantly correlated with the severity of oxygen desaturation. Therefore, nasal obstruction may play an important role in the pathophysiology of hypoxemia in OSA patients, especially in patients with moderate to severe OSA.

Keywords: nasal resistance, rhinomanometry, polysomnography, OSA

\section{Introduction}

Obstructive sleep apnea (OSA) is associated with repeated episodes of upper airway collapse during sleep, which leads to intermittent hypoxemia, microarousals, sleep fragmentation, and excessive daytime sleepiness. OSA-related high-frequency intermittent hypoxemia, which differs from low-frequency sustained hypoxemia as seen in chronic lung disease, results in ischemia-reperfusion injury and has established negative effects on cardiovascular health. ${ }^{1}$ These repetitive cycles of desaturationreoxygenation injury contribute to oxidative stress by formation of increased reactive oxygen species (ROS), which in turn causes devastating effects at the tissue level. Intermittent hypoxemia is now being considered as a main factor for diverse multiorgan morbidities, including cardiovascular disorder, metabolic malfunction, and neurodegenerative disease, and perhaps even in cancer progression. ${ }^{2-4}$

Multilevel upper airway obstruction is generally observed in OSA patients. The nose, which is the first component of the upper airway, accounts for more than $50 \%$ 
of total upper airway resistance. However, the role of nasal resistance as a causative factor for OSA has not been fully clarified. ${ }^{5}$ It is thought that nasal obstruction upstream exacerbates negative pressure of the oropharynx downstream, which in turn predisposes to pharyngeal collapse. Once nasal resistance surpasses a particular threshold, nasal breathing is less comfortable and natural, and a transition to oral breathing occurs. Unstable oral breathing causes a higher total upper airway resistance and exacerbates tongue base collapse. Additionally, reduced nasal breathing leads to deactivation of nasal receptors, inhibition of the nasal ventilatory reflex, and further decreased spontaneous ventilation. Nitric oxide (NO), an aerotransmitter generated in the nose, is a potent vasodilator for the lungs and plays an important role in regulating ventilation-perfusion balance. An increase in nasal resistance may cause a decrease in NO delivery to the lungs and further precipitate hypoxemia. ${ }^{6}$

Several mechanisms have been postulated to explain the relationship between nasal resistance and OSA. However, the role of nasal obstruction in relation to hypoxemia in OSA has not been fully elucidated. In the current study, the correlation between nasal resistance and oximetry variables was further evaluated in depth. According to the International Committee on standardization of rhinomanometry, the resistance is generally measured at a pressure of $150 \mathrm{~Pa}$. However, in some physiologic studies, if the pressure level of $150 \mathrm{~Pa}$ cannot be reached, the lower pressure levels of 75 and $100 \mathrm{~Pa}$ can be measured instead but should be specified. ${ }^{7}$ Recently, the majority of research centers utilized the pressure levels of 75 and $150 \mathrm{~Pa}$ to express nasal resistance. ${ }^{8}$ However, the pressure level which was used to determine the nasal resistance may be varied between distinct ethnic groups. A pressure level of $150 \mathrm{~Pa}$ was frequently chosen in the studies with Caucasian subjects, ${ }^{9-11}$ while pressure levels of 75 and $100 \mathrm{~Pa}$ were used extensively in the studies with Chinese and Japanese subjects. ${ }^{12-14}$ Some thorough studies even measured nasal resistance at pressure levels of 75,150 , and $300 \mathrm{~Pa}$ to carry out a more comprehensive analysis. ${ }^{15,16}$ Therefore, all pressure levels of 75, 150, and $300 \mathrm{~Pa}$ were included in the current study.

The purpose of this study was to evaluate the correlation between nasal resistance and oximetry variables in polysomnography to better realize the role of nasal obstruction in the pathophysiology of OSA.

\section{Materials and Methods}

\section{Subjects and Measurements}

From January 2017 to December 2018, 88 patients aged $\geq 20$ years and apnea-hypopnea index (AHI) $\geq 5$ episodes per hour of sleep with OSA-related symptoms were enrolled in this study. Exclusion criteria were as follows: (1) previous nasal surgery, nasal polyps, adenoid hypertrophy, sinonasal or upper aerodigestive tract neoplasm, (2) complete unilateral nasal obstruction which may potentially interfere with measurements of nasal resistance, and (3) neurodegenerative disorders or pulmonary disease. Patients were educated to discontinue oral and topical nasal medications 1 week before polysomnography and rhinomanometry. All patients received a detailed otolaryngologic evaluation, including clinical history and physical examination, nasopharyngoscopy, active anterior rhinomanometry, and nocturnal polysomnography. This study was approved by the Institutional Review Board of Taipei Tzu Chi Hospital (no. 08-XD-064). All procedures were conducted in accordance with the Declaration of Helsinki.

\section{Overnight Polysomnography}

Enrolled patients underwent standard overnight type I polysomnography for at least 6 hours. Sleep recordings were based on the criteria of the American Academy of Sleep Medicine. ${ }^{17}$ The AHI was calculated as the total number of apnea and hypopnea events per hour of sleep. The oxygen desaturation index (ODI) was calculated as the number of events of oxygen desaturation of $3 \%$ or more per hour of sleep. Percentage of total time with oxygen saturation level lower than $90 \%(\mathrm{~T}<90 \%)$ and minimal oxygen saturation (Minimal $\mathrm{SaO} 2$ ) were recorded.

\section{Rhinomanometric Measurements}

Tests were performed using the NR6 rhinomanometer (GM Instruments Ltd, Glasgow, UK). Nasal pressure and airflow were measured by active anterior rhinomanometry, which required patients to generate airflow via the nose by voluntary inspiration. All procedures were performed in accordance with the International Committee on Standardization of Rhinomanometry. ${ }^{7}$ A pressure sensing tube was inserted into the nostril with tight seal to the nasal alae without distortion of the external nose to measure pressure, while the other nostril was left patent to assess airflow by a pneumotachometer. All patients were educated to rest in the air-conditioned room for at least 5 
minutes, which allowed better acclimation to the room environment. All measurements were obtained at pressures of 75,150 , and $300 \mathrm{~Pa}$, with the patients first in the seated position, and then in the supine position during wakefulness. In order to prevent the influence of nasal cycle, all procedures were finished in 25 minutes. All nasal parameters were measured at least three times and then averaged for detailed analysis. Anterior rhinomanometry can only measure the resistance of one nasal passage one at a time, and the total resistance must be calculated from the formula. Overall nasal resistance was derived using the universally used formula below:

Total nasal resistance $=$ (right nasal resistance $\mathrm{x}$ left nasal resistance)/(right nasal resistance + left nasal resistance). ${ }^{18}$

\section{Statistical Analysis}

Polysomnographic and rhinomanometric data were expressed as mean \pm standard deviation. Categorical data are expressed as numbers and percentages. Differences between nasal resistance in the seated and supine positions were compared using the Wilcoxon signed-rank test. Correlations between oximetric variables and nasal resistance in the seated and supine positions were analyzed via Spearman's rank correlation coefficient. Spearman's rank correlation coefficient and R square were computed for the multiple linear regression analysis. Differences were considered statistically significant if $\mathrm{P}<0.05$. SPSS version 20.0 (IBM Corp., Armonk, NY) was used for all statistical calculations.

\section{Results}

Sixty-two males and 26 females were enrolled in this study with a mean age of 49.53 years. ODI ranged from 0.9 to 114.6 , with a mean of 36.0 events $/$ hr. The $\mathrm{T}<90 \%$ ranged from $0.1 \%$ to $75.3 \%$, with a mean of $18.2 \%$. Minimal $\mathrm{SaO} 2$ ranged from $53.0 \%$ to $92.0 \%$, with a mean of $74.8 \%$ (Table 1 ).

There were significant differences in nasal resistance between the seated and supine positions at pressures of 75 and $150 \mathrm{~Pa}$ (Table 2, $\mathrm{p}=0.001$ and 0.006 , respectively). While a significant increase in nasal resistance was observed at pressures of 75 and $150 \mathrm{~Pa}$ from the seated to the supine position, there was no statistically significant difference in nasal resistance between the seated and supine positions at pressures of $300 \mathrm{~Pa}$ (Table 2, $\mathrm{p}=0.216$ ).

As shown in Table 3, Figures 1 and 2, significant positive correlations were noted between nasal resistance
Table I Patient Characteristics

\begin{tabular}{|c|c|c|}
\hline Variables & Mean \pm SD & Range \\
\hline Males, n (\%) & 62 (70.5\%) & \\
\hline Females, n (\%) & 26 (29.5\%) & \\
\hline Age (year) & $49.53 \pm 12.74$ & $22-77$ \\
\hline BMI $\left(\mathrm{kg} / \mathrm{m}^{2}\right)$ & $27.77 \pm 4.64$ & $|5.60-4| .00$ \\
\hline ESS & $10.30 \pm 4.50$ & $0-22$ \\
\hline AHI (events/hr) & $42.30 \pm 27.48$ & $5.00-133.80$ \\
\hline ODI (events/hr) & $35.97 \pm 27.51$ & $0.90-114.60$ \\
\hline Minimal $\mathrm{SaO}_{2}(\%)$ & $74.82 \pm|5.6|$ & $53.00-92.00$ \\
\hline $\mathrm{T}<90 \%$ (\%) & $18.21 \pm 20.90$ & $0.10-75.30$ \\
\hline
\end{tabular}

Notes: Data are expressed as means \pm standard deviation (SD).

Abbreviations: BMI, body mass index; ESS, Epworth Sleepiness Scale; AHI, apneahypopnea index; ODI, oxygen desaturation index; Minimal $\mathrm{SaO}_{2}$, minimal oxygen saturation; $\mathrm{T}<90 \%$, the percentage of total time with oxygen saturation level lower than $90 \%$.

Table 2 Comparison of Nasal Resistance in the Seated Position and the Supine Position at Pressures of 75, 150, and 300 Pascal

\begin{tabular}{|c|l|l|}
\hline & Mean \pm SD & P \\
\hline $\begin{array}{c}\text { NR75 } \\
\text { Seated } \\
\text { Supine }\end{array}$ & $0.155 \pm 0.071$ & \\
\hline NRI50 & $0.193 \pm 0.164$ & $0.00 I^{*}$ \\
Seated & & \\
Supine & $0.202 \pm 0.797$ & $0.006^{*}$ \\
\hline NR300 & $0.255 \pm 0.171$ & \\
Seated & & \\
Supine & $0.262 \pm 0.138$ & 0.216 \\
\hline
\end{tabular}

Notes: Data are expressed as means \pm standard deviation (SD); $* \mathrm{P}<0.05$.

Abbreviation: NR75, NRI50, NR300, nasal resistance at 75, I50 and 300 pascal.

in the supine position at $75 \mathrm{~Pa}$ (SupineNR75) and oximetry variables, including ODI and $\mathrm{T}<90 \%(\mathrm{P}=0.015$ and 0.012). In addition, a positive agreement was noted between SupineNR75 and AHI $(\mathrm{P}=0.025)$. On the contrary, no significant correlations were found between nasal resistance in the seated position at all pressure levels $(75$, 150 and $300 \mathrm{~Pa}$ ) and oximetry variables.

The study group was further divided into two subgroups, including mild OSA and moderate to severe OSA. Significant positive correlations still existed between SupineNR75 and oximetry variables in moderate to severe OSA. However, no significant correlations were noted between SupineNR75 and oximetry variables in mild OSA (Table 4).

Multiple linear regression analysis was utilized to determine independent predictors for severity of oxygen desaturation. BMI and SupineNR75 were recognized as independent 
Table 3 Spearman Correlation Between Oximetry Variables and Nasal Resistance in the Seated Position and in the Supine Position at Pressures of 75,150 , and 300 Pascal

\begin{tabular}{|c|c|c|c|c|c|c|c|c|}
\hline & \multicolumn{2}{|l|}{ AHI } & \multicolumn{2}{|l|}{ ODI } & \multicolumn{2}{|c|}{ Minimal SaO2 } & \multicolumn{2}{|c|}{$\mathrm{T}<90 \%$} \\
\hline & $r_{s}$ & $\mathbf{P}$ & $r_{s}$ & $\mathbf{P}$ & $r_{s}$ & $\mathbf{P}$ & $r_{s}$ & $\mathbf{P}$ \\
\hline \multicolumn{9}{|l|}{ Seated } \\
\hline NR75 & 0.095 & 0.381 & 0.163 & 0.135 & -0.055 & 0.616 & 0.168 & 0.124 \\
\hline NRI50 & 0.018 & 0.875 & 0.082 & 0.484 & -0.016 & 0.892 & 0.062 & 0.599 \\
\hline NR300 & 0.062 & 0.635 & 0.126 & $0.34 I$ & -0.187 & 0.156 & 0.167 & 0.207 \\
\hline \multicolumn{9}{|l|}{ Supine } \\
\hline NR75 & 0.246 & $0.025^{*}$ & 0.269 & $0.015^{*}$ & -0.135 & 0.228 & 0.276 & $0.012 *$ \\
\hline NRI50 & 0.105 & 0.375 & 0.176 & 0.143 & -0.115 & $0.34 I$ & 0.226 & 0.058 \\
\hline NR300 & -0.026 & 0.846 & 0.058 & 0.666 & -0.044 & 0.746 & 0.063 & 0.642 \\
\hline
\end{tabular}

Note: $* \mathrm{P}<0.05$.

Abbreviations: $r_{s}$, Spearman correlation coefficient; $\mathrm{AHI}$, apnea-hypopnea index; ODI, oxygen desaturation index; $\mathrm{Minimal}$ SaO $\mathrm{O}_{2}$, minimal oxygen saturation; $\mathrm{T}<90 \%$, the percentage of total time with oxygen saturation level lower than $90 \%$; NR75, NRI50, NR300, nasal resistance at 75, 150 and 300 pascal.

predictors for ODI (Table 5). The results demonstrated that severity of oxygen desaturation, as defined by ODI, significantly correlated with BMI and SupineNR75 (Table 5).

\section{Discussion}

The pathogenic role of nasal resistance as a causative factor for OSA severity has been studied for years. However, the relationship between nasal resistance and OSA severity is still controversial. ${ }^{19}$ Some studies have reported possible correlations between OSA severity and nasal resistance, ${ }^{11,20-22}$ while many others failed to find any association between sleep-disordered breathing and nasal resistance. ${ }^{23,24}$ The discrepancy could be partially explained by the different postures studied when nasal resistance was measured, either in the seated or the supine position. Studies that revealed positive correlations between OSA severity and nasal resistance mostly measured results in the supine position, ${ }^{11,20,21}$ which is more comparable to physiologic conditions during sleep. In the current study, we evaluate nasal obstruction both in the seated and supine positions. Similar to the outcomes of a previous study, ${ }^{16}$ our results showed significantly higher nasal resistance in the supine position compared to that of the seated position at 75 and $150 \mathrm{~Pa}$. In the supine position, nasal resistance tends to increase compared to that of the seated position in consequence of postural reflexes, as well as hydrostatic pressure in the nasal venous circulation. $^{25}$

In order to perform a thorough evaluation of the role of nasal resistance in OSA-related hypoxemia, all pressure levels of 75, 150, and $300 \mathrm{~Pa}$ were enrolled in the current study. The results revealed that one subject $(1.1 \%)$ could not reach $75 \mathrm{~Pa}, 11$ subjects (12.5\%) could not reach 150 $\mathrm{Pa}$, and 27 subjects (30.7\%) could not reach $300 \mathrm{~Pa}$ under natural breathing in the seated position. Five subjects (5.7\%) could not reach $75 \mathrm{~Pa}, 15$ subjects (17\%) could not reach $150 \mathrm{~Pa}$, and 29 subjects (33\%) could not reach $300 \mathrm{~Pa}$ under natural breathing in the supine position. In summary, the higher the pressure level, the more the proportion of subjects failed to obtain resistance data. Therefore, $300 \mathrm{~Pa}$ may not be proper for the clinical practice of rhinomanometry. To date, the clinical relevance of $300 \mathrm{~Pa}$ has never been reported in the literature. In this study, the results showed that nasal resistance measured at a pressure of $75 \mathrm{~Pa}$ in the supine position significantly correlated with oximetric variables. Therefore, $75 \mathrm{~Pa}$ may be a reasonable pressure level for rhinomanometry in Asian subjects.

To the best of our knowledge, this is the first study to focus mainly on the relationship between nasal resistance and oximetric variables. Our results indicated significant correlations between SupineNR75 and oximetric variables (ODI and $\mathrm{T}<90 \%$ ). Multivariate analysis showed that SupineNR75 and BMI were predictive factors of increased ODI. Possible mechanisms involved in the development of nasal obstruction-related hypoxemia are the decreased nasal ventilatory reflex and reduced delivery of NO.

The efficacy of nasal surgery, such as septoplasty, inferior turbinate reduction, endoscopic sinus surgery, and nasal valve surgery for the treatment of OSA has been widely discussed in the literature. ${ }^{26-29}$ Although nasal surgery alone is not considered a curative treatment for OSA, it may ameliorate quality of life and snoring in a subgroup of OSA patients, and potentially improve 


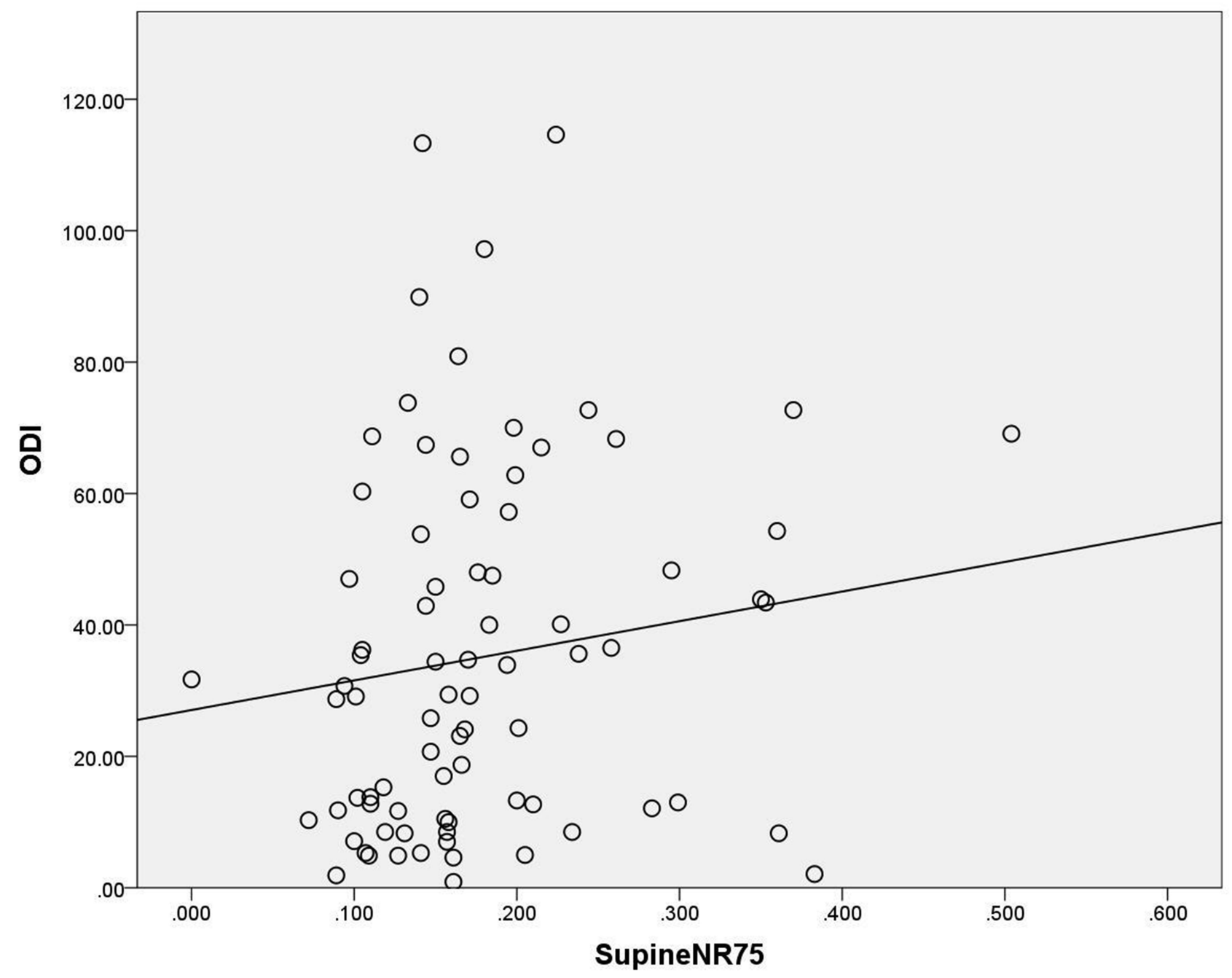

Figure I Significant positive correlation was noted between nasal resistance in the supine position at $75 \mathrm{~Pa}($ SupineNR75) and oxygen desaturation index $(\mathrm{ODI}, \mathrm{P}=0.0 \mathrm{I} 5)$.

positive airway pressure therapy compliance and tolerance. ${ }^{6}$ Nakata et al indicated that the lowest nocturnal oxygen saturation and Epworth Sleepiness Scale (ESS) significantly improved after nasal surgery, although AHI remained unchanged. ${ }^{14}$ Quality of life impairment, including certain sinonasal symptoms, is significant among OSA patients, with notable improvement following nasal surgery. ${ }^{30,31}$ Improvement in quality of life may be explained by the increase of overall blood oxygenation after nasal surgery. Recent studies have evaluated the unfavorable effect of nasal septal deviation on cardiovascular health, which indicated that nasal obstruction resulted in chronic alveolar hypoxemia and hypercapnia. As a result, pulmonary hypertension and right ventricular failure were more likely to occur. ${ }^{32}$ Simsek et al found that both peripheral arterial oxygen saturation and right ventricular myocardial function improved significantly after nasal surgery, which further lends support to the contributory role of nasal resistance in hypoxemia. ${ }^{33}$ Similarly, Düzenli et al studied antioxidant enzyme levels, including catalase, superoxide dismutase, and glutathione, before and after septoplasty. They concluded that antioxidant enzyme levels were lower in patients with nasal septal deviation compared to controls. Septoplasty led to an increase in antioxidative stress markers. ${ }^{34,35}$ In summary, previous studies illustrated the efficacy of nasal surgery in the improvement of the lowest nocturnal oxygen saturation, arterial oxygen saturation, right ventricular myocardial function, and antioxidant enzyme levels, which indirectly substantiated the role of nasal resistance in OSA-related hypoxemia.

There are several limitations in this study. First, anterior rhinomanometry is unable to obtain nasal resistance if one nasal passage is completely obstructed. Since subjects 


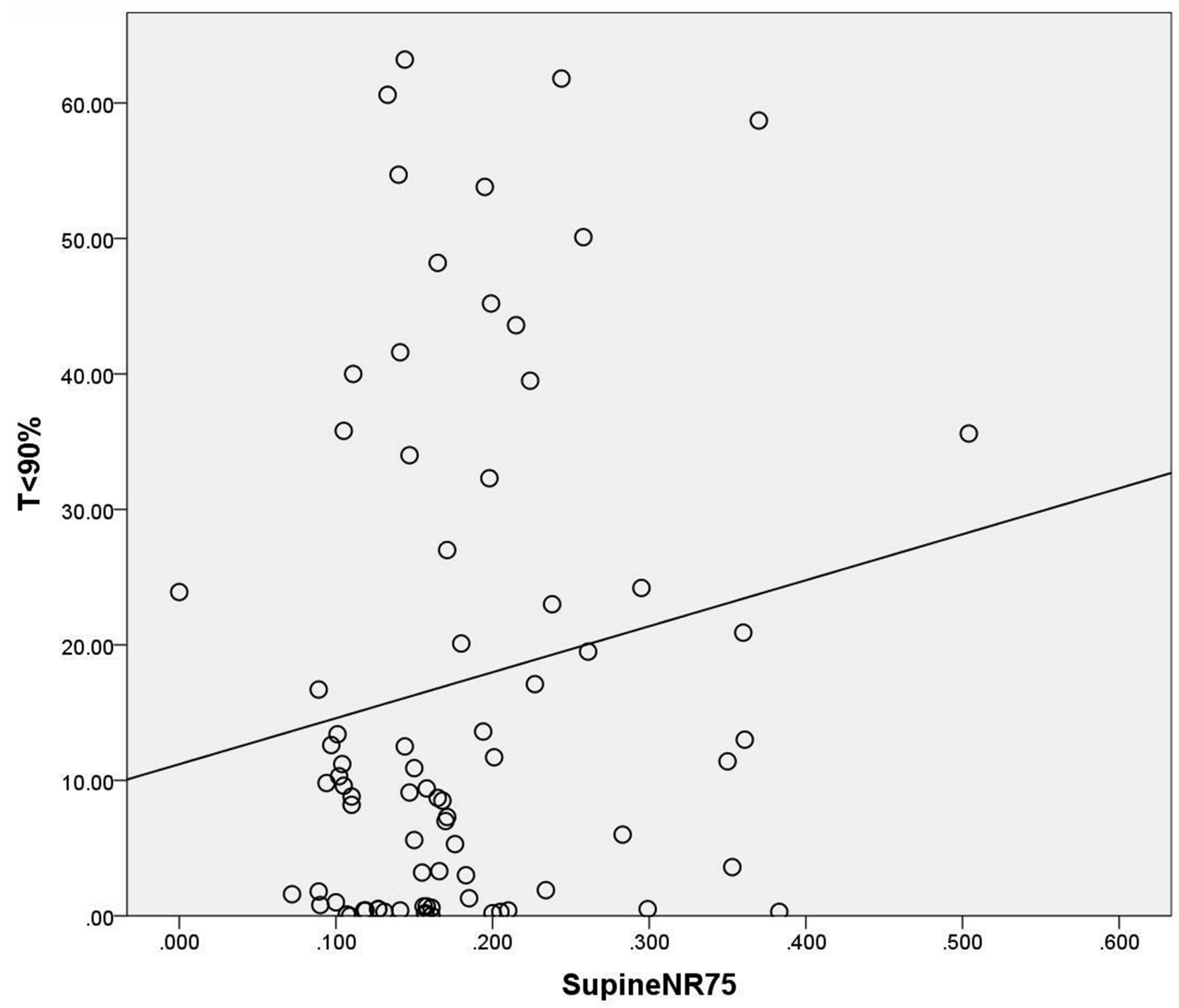

Figure 2 Significant positive correlation was noted between nasal resistance in the supine position at $75 \mathrm{~Pa}$ (SupineNR75) and the percentage of total time with oxygen saturation level lower than $90 \%(T<90 \%, P=0.012)$.

with complete unilateral nasal obstruction or severely deviated nasal septum were excluded in this study, the results may not fully represent the whole population of OSA patients. Nevertheless, active rhinomanometry is recommended by the International Committee on Standardization of Rhinomanometry as the most commonly used method to detect nasal resistance. ${ }^{7}$ Second, periodic congestion and decongestion of the nasal venous

Table 4 Spearman Correlation Between Oximetry Variables and Nasal Resistance in the Supine Position at Pressures of 75 Pascal in Mild and Moderate to Severe OSA

\begin{tabular}{|l|l|l|l|l|l|l|l|l|}
\hline & \multicolumn{2}{l}{ AHI } & \multicolumn{2}{l|}{ ODI } & \multicolumn{2}{l|}{ Minimal SaO2 } & \multicolumn{2}{l|}{ T<90\% } \\
\cline { 2 - 8 } & $\boldsymbol{r}_{\mathbf{s}}$ & $\mathbf{P}$ & $\boldsymbol{r}_{\mathbf{s}}$ & $\mathbf{P}$ & $\boldsymbol{r}_{\mathbf{s}}$ & $\mathbf{P}$ & $\boldsymbol{r}_{\mathbf{s}}$ & $\mathbf{P}$ \\
\hline SupineNR75 & & & & & & & \\
Mild OSA & 0.121 & 0.694 & 0.064 & 0.842 & -0.438 & 0.155 & 0.074 & 0.820 \\
Moderate to severe OSA & 0.248 & $0.041^{*}$ & 0.272 & $0.026 *$ & -0.109 & 0.380 & 0.265 & $0.030^{*}$ \\
\hline
\end{tabular}

Note: $* \mathrm{p}<0.05$.

Abbreviations: $r_{s}$, Spearman correlation coefficient; AHI, apnea-hypopnea index; ODI, oxygen desaturation index; Minimal SaO ${ }_{2}$, minimal oxygen saturation; $\mathrm{T}<90 \%$, the percentage of total time with oxygen saturation level lower than $90 \%$; SupineNR75, nasal resistance in the supine position at 75 pascal. 
Table 5 Multiple Linear Regression Analysis to Predict the Potential Variables for ODI

\begin{tabular}{|l|l|l|l|l|}
\hline Variables & B & $\boldsymbol{\beta}$ & $\mathbf{9 5 \%} \mathbf{C l}$ & $\mathbf{P}$ \\
\hline Sex & -3.660 & -0.063 & $-15.293-7.973$ & 0.533 \\
Age, years & 0.240 & 0.114 & $-0.202-0.681$ & 0.283 \\
BMI, kg/m2 & 2.830 & 0.476 & $1.589-4.070$ & $<0.001 *$ \\
ESS & 0.190 & 0.032 & $-0.981-1.361$ & 0.747 \\
MMS & -0.131 & -0.003 & $-10.091-9.829$ & 0.979 \\
SupineNR75 & 48.088 & 0.303 & $15.720-80.456$ & $0.004^{*}$ \\
\hline
\end{tabular}

Note: $* \mathrm{P}<0.05$

Abbreviations: BMI, body mass index; ESS, Epworth sleepiness scale; MMS, modified Mallampati score; SupineNR75, nasal resistance in the supine position at 75 pascal.

sinusoids, called nasal cycle, result in side to side fluctuation of nasal resistance between the left side and right side nasal cavity. However, total nasal resistance remains relatively constant despite side to side variation of unilateral nasal resistance. ${ }^{36,37}$ In this study, total nasal resistance was obtained to minimize the influence of nasal cycle. Last, the history of menstrual cycle and gynecological medications was not recorded in the present study. The impact of contraceptive pills or hormone replacement therapy on nasal airway resistance may be neglected. However, earlier studies failed to discover any significant correlation between the menstrual cycle and nasal airflow. $^{38,39}$

\section{Conclusion}

The role of nasal obstruction as a causative factor for OSA has not been fully elucidated in the literature. In this study, however, the results demonstrated that severity of oxygen desaturation, as defined with ODI, significantly correlated with BMI and SupineNR75. Nasal obstruction may play an important role in the pathophysiology of hypoxemia in OSA patients, especially in patients with moderate to severe OSA. The measurements of nasal resistance should be part of the comprehensive evaluation algorithm for OSA patients, and the corrective nasal surgery should be based on the results of rhinomanometry accordingly.

\section{Ethics Approval}

All procedures performed in this study were in accordance with the ethical standards of the Institutional Review Board of Taipei Tzu Chi Hospital (no. 08-XD-064). Patient-informed consent was waived because of the retrospective nature of this research. The patients' data were maintained with confidentiality and in compliance with the Declaration of Helsinki.

\section{Acknowledgments}

This study was funded by Taipei Tzu Chi Hospital, Buddhist Tzu Chi Medical Foundation (TCRD-TPE-109-28(2/2)).

\section{Disclosure}

The authors report no potential conflicts of interest for this work.

\section{References}

1. Eltzschig HK, Eckle T. Ischemia and reperfusion-from mechanism to translation. Nat Med. 2011;17(11):1391-1401. doi:10.1038/nm.2507

2. Garvey JF, Taylor CT, McNicholas WT. Cardiovascular disease in obstructive sleep apnoea syndrome: the role of intermittent hypoxia and inflammation. Eur Respir J. 2009;33(5):1195-1205. doi:10.1183/ 09031936.00111208

3. Akhan G, Ayik S, Songu M. Cerebral oxygenation during sleep in patients with obstructive sleep apnea: a near-infrared spectroscopy study. J Otolaryngol Head Neck Surg. 2012;41(6):437-442.

4. Dewan NA, Nieto FJ, Somers VK. Intermittent hypoxemia and OSA: implications for comorbidities. Chest. 2015;147(1):266-274. doi: $10.1378 /$ chest. $14-0500$

5. Georgalas $\mathrm{C}$. The role of the nose in snoring and obstructive sleep apnoea: an update. Eur Arch Otorhinolaryngol. 2011;268 (9):1365-1373. doi:10.1007/s00405-010-1469-7

6. Sharma S, Wormald JCR, Fishman JM, Andrews P, Kotecha BT. Rhinological interventions for obstructive sleep apnoea a systematic review and descriptive meta-analysis. J Laryngol Otol. 2019;133(3):168-176. doi:10.1017/S0022215119000240

7. Clement PA, Gordts F. Standardisation committee on objective assessment of the Nasal Airway IRS, Ers. Consensus report on acoustic rhinometry and rhinomanometry. Rhinology. 2005;43 (3):169-179.

8. Eccles R. A guide to practical aspects of measurement of human nasal airflow by rhinomanometry. Rhinology. 2011;49(1):2-10. doi:10.4193/Rhino10.065

9. Sin S, Wootton DM, McDonough JM, Nandalike K, Arens R. Anterior nasal resistance in obese children with obstructive sleep apnea syndrome. Laryngoscope. 2014;124(11):2640-2644. doi:10.10 02/lary. 24653

10. Toh ST, Lin CH, Guilleminault C. Usage of four-phase high-resolution rhinomanometry and measurement of nasal resistance in sleep-disordered breathing. Laryngoscope. 2012;122(10):23 43-2349. doi:10.1002/lary.23441

11. Passali FM, Bellussi L, Mazzone S, Passali D. Predictive role of nasal functionality tests in the evaluation of patients before nocturnal polysomnographic recording. Acta Otorhinolaryngol Ital. 2011;31 (2):103-108

12. Ren L, Zhang L, Duan S, Zhang W, Zhang Y. Nasal airflow resistance measured by rhinomanometry in a healthy population of China. Int Forum Allergy Rhinol. 2018;8(11):1308-1314. doi:10.1002/ alr. 22177

13. Kobayashi R, Miyazaki S, Karaki M, et al. Evaluation of adenotonsillectomy and tonsillectomy for pediatric obstructive sleep apnea by rhinomanometry and the OSA-18 questionnaire. Acta Otolaryngol. 2014;134(8):818-823. doi:10.3109/00016489.2014.905703

14. Nakata S, Noda A, Yagi H, et al. Nasal resistance for determinant factor of nasal surgery in CPAP failure patients with obstructive sleep apnea syndrome. Rhinology. 2005;43(4):296-299.

15. Hsu YB, Liu SY, Lan MY, Huang YC, Tzeng IS, Lan MC. Role of rhinomanometry in the prediction of therapeutic positive airway pressure for obstructive sleep apnea. Respir Res. 2020;21(1):115. doi:10.1186/s12931-020-01382-4 
16. Hueto J, Santaolalla F, Sanchez-Del-Rey A, Martinez-Ibarguen A. Usefulness of rhinomanometry in the identification and treatment of patients with obstructive sleep apnoea: an algorithm for predicting the relationship between nasal resistance and continuous positive airway pressure a retrospective study. Clin Otolaryngol. 2016;41 (6):750-757. doi:10.1111/coa.12639

17. Berry RB, Budhiraja R, Gottlieb DJ, et al. Rules for scoring respiratory events in sleep: update of the 2007 AASM manual for the scoring of sleep and associated events. Deliberations of the sleep apnea definitions task force of the american academy of sleep medicine. J Clin Sleep Med. 2012;8(5):597-619. doi:10.5664/ jcsm. 2172

18. Cole P, Naito K, Chaban R, Ayiomamitis A. Unilateral and bilateral nasal resistances. Rhinology. 1988;26(3):209-216.

19. Migueis DP, Thuler LC, Lemes LN, Moreira CS, Joffily L, AraujoMelo MH. Systematic review: the influence of nasal obstruction on sleep apnea. Braz J Otorhinolaryngol. 2016;82(2):223-231. doi:10. 1016/j.bjorl.2015.05.018

20. Virkkula P, Maasilta P, Hytonen M, Salmi T, Malmberg H. Nasal obstruction and sleep-disordered breathing: the effect of supine body position on nasal measurements in snorers. Acta Otolaryngol. 2003;123(5):648-654. doi:10.1080/00016480310001493

21. Li HY, Wang PC, Hsu CY, Cheng ML, Liou CC, Chen NH. Nasal resistance in patients with obstructive sleep apnea. ORL J Otorhinolaryngol Relat Spec. 2005;67(2):70-74. doi:10.1159/ 000084337

22. Hsu YB, Lan MY, Huang YC, Kao MC, Lan MC. Association between breathing route, oxygen desaturation, and upper airway morphology. Laryngoscope. 2020. doi:10.1002/lary.28774

23. Miljeteig H, Hoffstein V, Cole P. The effect of unilateral and bilateral nasal obstruction on snoring and sleep apnea. Laryngoscope. 1992;102(10):1150-1152. doi:10.1288/00005537-199210000-00009

24. Atkins M, Taskar V, Clayton N, Stone P, Woodcock A. Nasal resistance in obstructive sleep apnea. Chest. 1994;105(4):1133-1135. doi:10.1378/chest.105.4.1133

25. Tsai KK, Yen CF, Chu YH, Wang HW. Using dynamic analysis of Laser-Doppler blood flowmetry to measure nasal mucosa bloody flow in postural changes. Rhinology. 2012;50(4):376-380. doi:10.4193/ Rhin 10.134

26. Kim ST, Choi JH, Jeon HG, Cha HE, Kim DY, Chung YS. Polysomnographic effects of nasal surgery for snoring and obstructive sleep apnea. Acta Otolaryngol. 2004;124(3):297-300. doi:10.1080/00016480410016252
27. Virkkula P, Bachour A, Hytonen M, et al. Snoring is not relieved by nasal surgery despite improvement in nasal resistance. Chest. 2006;129(1):81-87. doi:10.1378/chest.129.1.81

28. Li HY, Lee LA, Wang PC, Chen NH, Lin Y, Fang TJ. Nasal surgery for snoring in patients with obstructive sleep apnea. Laryngoscope. 2008;118(2):354-359. doi:10.1097/MLG.0b013e318158f73f

29. Nakata S, Noda A, Yasuma F, et al. Effects of nasal surgery on sleep quality in obstructive sleep apnea syndrome with nasal obstruction. Am J Rhinol. 2008;22(1):59-63. doi:10.2500/ajr.2008.22.3120

30. Kuan EC, Tajudeen BA, Peng KA, Wang MB. Sinonasal outcomes in obstructive sleep apnea syndrome. Laryngoscope. 2015;125 (11):2617-2620. doi:10.1002/lary.25411

31. Tajudeen BA, Brooks SG, Yan $\mathrm{CH}$, et al. Quality-of-life improvement after endoscopic sinus surgery in patients with obstructive sleep apnea. Allergy Rhinol (Providence). 2017;8(1):25-31. doi:10.2500/ ar.2017.8.0195

32. Ozkececi G, Akci O, Bucak A, et al. The effect of septoplasty on pulmonary artery pressure and right ventricular function in nasal septum deviation. Eur Arch Otorhinolaryngol. 2016;273(11):37 47-3752. doi:10.1007/s00405-016-4042-1

33. Simsek Z, Simsek E. Does nasal surgery affect right ventricular myocardial functions at the tissue level in patients with nasal septum deviation? J Clin Med. 2018;7:8. doi:10.3390/jcm7080186

34. Ekinci A, Karatas D, Yetis A, Demir E, Ozcan M. The effects of septoplasty surgery on serum oxidative stress levels. Eur Arch Otorhinolaryngol. 2017;274(7):2799-2802. doi:10.1007/s00405017-4546-3

35. Duzenli U, Bozan N, Sonkaya Y, Cetin YS, Demir H. Evaluation of the relationship between nasal septum deviation and oxidative stress markers. J Craniofac Surg. 2019;30(3):851-853. doi:10.1097/ SCS.0000000000005244

36. Flanagan P, Eccles R. Spontaneous changes of unilateral nasal airflow in man. A re-examination of the 'nasal cycle'. Acta Otolaryngol. 1997;117(4):590-595. doi:10.3109/00016489709113443

37. Hanif J, Jawad SS, Eccles R. The nasal cycle in health and disease. Clin Otolaryngol Allied Sci. 2000;25(6):461-467. doi:10.1046/ j.1365-2273.2000.00432.x

38. Grillo C, La Mantia I, Triolo C, et al. Rhinomanometric and olfactometric variations throughout the menstrual cycle. Ann Otol Rhinol Laryngol. 2001;110(8):785-789. doi:10.1177/000348940111000816

39. Driver HS, McLean H, Kumar DV, Farr N, Day AG, Fitzpatrick MF. The influence of the menstrual cycle on upper airway resistance and breathing during sleep. Sleep. 2005;28(4):449-456. doi:10.1093/ sleep/28.4.449
Nature and Science of Sleep

\section{Publish your work in this journal}

Nature and Science of Sleep is an international, peer-reviewed, open access journal covering all aspects of sleep science and sleep medicine, including the neurophysiology and functions of sleep, the genetics of sleep, sleep and society, biological rhythms, dreaming, sleep disorders and therapy, and strategies to optimize healthy sleep.
The manuscript management system is completely online and includes a very quick and fair peer-review system, which is all easy to use. Visit http://www.dovepress.com/testimonials.php to read real quotes from published authors. 